\title{
Antiphospholipid antibodies and anticoagulant therapy: capillaroscopic findings
}

Giorgia Ferrari ${ }^{1 \dagger}$, Emanuele Gotelli ${ }^{1 \dagger}$, Sabrina Paolino ${ }^{1}$, Giampaola Pesce ${ }^{2}$, Luca Nanni ${ }^{3}$, Barbara Maria Colombo ${ }^{4}$, Greta Pacini ${ }^{1}$, Carlotta Schenone ${ }^{1}$, Carmen Pizzorni ${ }^{1}$, Alberto Sulli ${ }^{1}$, Vanessa Smith ${ }^{5,6+}$ and Maurizio Cutolo ${ }^{1 * \dagger}$ (D)

\begin{abstract}
Background: Antiphospholipid syndrome (APS) is a systemic autoimmune disease characterized by specific vascular and obstetric manifestations and by antiphospholipid antibodies (aPL) positivity. Microvascular damage in the course of APS and "aPL carrier" patients without symptoms is poorly investigated.

Objectives: This study aims to compare nailfold videocapillaroscopy (NVC) microvascular parameters in APS patients and non-symptomatic "aPL carriers" and to investigate their possible correlations with different aPL subtypes.

Methods: NVC was performed during standard evaluations in 18 APS patients (mean age $50 \pm 13.8$ years), 24 "aPL carriers" without symptoms (mean age $46.4 \pm 16.4$ years), and 18 control patients (CTR) (mean age $74 \pm$ 12.5 years) taking oral anticoagulants for non-immunological indications (i.e., cardiovascular accidents). All patients were investigated for the presence of dilated capillaries, giant capillaries, microhemorrhages, capillary loss, and further non-specific/specific abnormalities (i.e., branched "bushy" capillaries, sign of neoangiogenesis) by NVC. Every alteration was also classified according to a semi-quantitative score. Lupus anticoagulant, anticardiolipin antibodies, and antibeta2 glycoprotein I antibodies were tested in each patient.

Results: APS patients showed at NVC increased frequency of microhemorrhages $(p=0.039)$-particularly a "comb-like" pattern (parallel hemorrhages) $(p=0.002)$ - than "aPL carriers". Of note, there were no significant differences concerning the isolated number of microhemorrhages between APS and the CTR group ( $p=$ $0.314)$, but "comb-like" hemorrhages were significantly more frequent in the APS group $(p=0.034)$. Not any significant correlation was found between the aPL subtypes and NVC parameters.
\end{abstract}

\footnotetext{
* Correspondence: mcutolo@unige.it

${ }^{\dagger}$ Giorgia Ferrari and Emanuele Gotelli shared first name

†Vanessa Smith and Maurizio Cutolo shared last name

'Laboratory of Experimental Rheumatology and Academic Division of Clinical

Rheumatology, Department of Internal Medicine and Specialties (DiMl),

University of Genova, IRCCS San Martino Polyclinic, Viale Benedetto XV, $n^{\circ} 6$ -

16132 Genoa, Italy

Full list of author information is available at the end of the article
}

(c) The Author(s). 2021 Open Access This article is licensed under a Creative Commons Attribution 4.0 International License, which permits use, sharing, adaptation, distribution and reproduction in any medium or format, as long as you give appropriate credit to the original author(s) and the source, provide a link to the Creative Commons licence, and indicate if changes were made. The images or other third party material in this article are included in the article's Creative Commons licence, unless indicated otherwise in a credit line to the material. If material is not included in the article's Creative Commons licence and your intended use is not permitted by statutory regulation or exceeds the permitted use, you will need to obtain permission directly from the copyright holder. To view a copy of this licence, visit http://creativecommons.org/licenses/by/4.0/ The Creative Commons Public Domain Dedication waiver (http://creativecommons.org/publicdomain/zero/1.0/) applies to the data made available in this article, unless otherwise stated in a credit line to the data. 
Conclusions: APS patients showed significantly a greater number of non-specific NVC abnormalities than "aPL carriers", particularly the "comb-like" NVC pattern. Oral anticoagulants may represent a confounding factor for isolated microhemorrhages. Not any correlation was found between aPL subtypes and NVC parameters. Further investigations are needed to better characterize the microvascular endothelium damage induced by aPL.

Keywords: Nailfold capillaroscopy, Antiphospholipid syndrome, Connective tissue diseases, Systemic sclerosis, Systemic lupus erythematosus, Anticoagulant therapy

\section{Introduction}

Antiphospholipid syndrome (APS) is a systemic autoimmune disease characterized by arterial and/or venous thrombosis and/or obstetric morbidity, associated with the presence in the serum of specific autoantibodies, called antiphospholipid antibodies (aPL) [1]. The aPL used as diagnostic criteria for APS include anticardiolipin antibodies (aCL), antibeta2 glycoprotein I antibodies (anti-b2GPI), and lupus anticoagulant (LAC) [2]. A single, double, or triple aPL positivity of an individual is defined as "aPL profile" and predicts the onset of macrovascular thrombosis as well as may influence the treatment strategy. Importantly, subjects with isolated detection of aPL in absence of clinical thrombotic manifestations cannot be classified as APS patients, but only as "aPL carriers" [3, 4].

To date, APS microangiopathy is poorly characterized. Nailfold videocapillaroscopy (NVC) has been performed to assess microcirculation in these patients and the most reported alterations are capillary tortuosity and microhemorrhages [5].

Multiple hemorrhages from normal shaped capillaries, which appear parallel/linear and arranged perpendicularly to the nailfold bed, are called "comb-like" hemorrhages and are suggestive of APS (Fig. 1) [6]. However, the correlation of these NVC non-specific abnormalities

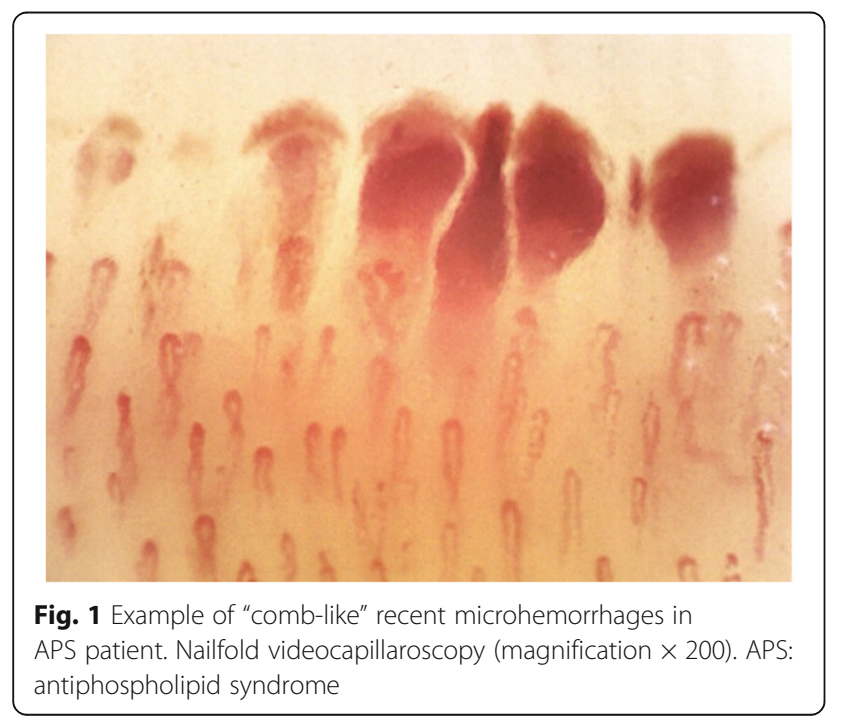

with specific aPL subtypes has always been contrasting $[7,8]$. Moreover, not any data about NVC abnormalities in "aPL carriers" is available to date.

Therefore, the aim of this study was the characterization of the microvascular damage in APS patients and "aPL carriers", investigating possible correlations between NVC microvascular parameters and different aPL subtypes. A control group of patients (CTR) on regular warfarin therapy for cardiovascular indications without aPL positivity has been also taken into account, in order to exclude possible NVC alterations due to anticoagulant therapy.

\section{Methods}

\section{Study population}

Eighteen APS patients (mean age $50 \pm 13.8$ SD years, 13 females and 5 males), twenty-four "aPL carriers" (mean age $46.4 \pm 16.4$ SD years, 23 females and 1 male), and eighteen CTR patients (mean age $74 \pm 12.5$ SD years, 8 females and 10 males) underwent NVC evaluation during their standard evaluations at the Rheumatology Department of Genoa University (Italy).

The complete medical history (including episodes of vascular thrombosis, pregnancy-related morbidity, anticoagulant therapy) and laboratory findings of enrolled patients were available in their clinical files.

APS diagnosis was made according to revised 2006 Sapporo classification criteria [2]. APS patients had either a primary syndrome or a secondary APS related to systemic lupus erythematosus (SLE-2019 EULAR/ACR criteria) [9]. Patients with an established diagnosis of systemic sclerosis ( $\mathrm{SSc})$, Sjögren's syndrome $(\mathrm{SjS})$, mixed connective tissue disease (MCTD), and idiopathic inflammatory myopathy (IIM) were excluded from the study [10-13].

CTR patients were on warfarin therapy for either atrial fibrillation (stable international normalized ratio (INR) from 2 to 3), mechanical heart valve implant (stable INR from 2.5 to 3.5 ), and/or deep venous thrombosis (stable INR from 2 to 3), and they had a negative aPL profile. Exclusion criteria of CTR patients were connective tissue diseases (CTDs), Raynaud's phenomenon, and recent traumatic events to their hands.

Clinical and immunological parameters of enrolled patients are summarized in Tables 1 and 2. 
This retrospective study was conducted in accordance with the principles of the Declaration of Helsinki and Good Clinical Practice. All the patients signed the mandatory written informed consent to manage their clinical data according to the rules of the Hospital/University at the time of their first visit in the Clinic.

\section{Antiphospholipid antibodies detection}

ACL and anti-b2GPI antibodies of IgG and/or IgM isotype have been measured by a standardized ELISA, according to recommended procedures (PerkinElmer, Euroimmun, MA, USA). They were considered positive if present in serum or plasma, in a medium or high titer (either $>40$ IgM or IgG phospholipid units or $>99^{\text {th }}$ centile), on two or more occasions, at least 12 weeks apart.

LAC was detected according to the International Society on Thrombosis and Hemostasis guidelines and considered positive if present in the plasma, on two or more occasions, at least 12 weeks apart [2].

\section{Nailfold videocapillaroscopy}

NVC has been performed by the same physician (CP) using an optical probe with a $\times 200$ magnification lens connected to picture analysis software (Videocap, DS Medica, Milan, Italy).

According to the standardized procedures, each patient remained in the test room for a minimum of 15 min before the NVC at the temperature of $20-22^{\circ} \mathrm{C}$. Two pictures of the 2-mm area in the middle of the nailfold bed of all the fingers, thumbs excluded, have been collected for each subject [14]. The following capillaroscopic parameters have been assessed: normal capillaries (including non-specific abnormalities: hairpin-shaped, tortuous, or crossing capillaries with branch diameters < $20 \mu \mathrm{m}$ ), dilated capillaries (irregular or homogeneous increase of capillary diameter between 20 and $50 \mu \mathrm{m}$ ), giant capillaries (homogeneously dilated normal shaped loops with a diameter $\geq 50 \mu \mathrm{m})$, microhemorrhages (dark masses attributable to hemosiderin deposit) with particular attention to "comb-like" hemorrhages, abnormal shapes (i.e., branched "bushy" capillaries, sign of neoangiogenesis), and capillary number reduction. A validated semi-quantitative rating scale has been adopted to score each NVC capillary abnormality detected ( 0 , no changes; $1,<33 \%$ of capillary alterations/reduction; $2,33-66 \%$ of capillary

Table 1 Clinical and immunological characteristics of APS patients, "aPL carriers", and CTR patients

\begin{tabular}{|c|c|c|c|}
\hline & APS & "aPL carriers" & CTR \\
\hline Total patients & 18 & 24 & 18 \\
\hline Female-male sex & $13-5$ & $23-1$ & $8-10$ \\
\hline Age (years, mean $\pm S D)$ & $50 \pm 13.8$ & $46.4 \pm 16.4$ & $74 \pm 12.5$ \\
\hline Disease duration (years, mean \pm SD) & $7.6 \pm 7.7$ & - & - \\
\hline Primary-secondary forms & $12-6$ & $17-7$ & - \\
\hline Arterial/venous thrombosis & 16/18 (88.9) & - & $9(50.0)$ \\
\hline Pregnancy morbidity & $3 / 13(23.1)$ & - & - \\
\hline Atrial fibrillation & - & - & $6(33.3)$ \\
\hline Mechanical heart valves & - & - & $3(16.7)$ \\
\hline Arterial hypertension & 6 & 8 & 6 \\
\hline Diabetes mellitus & 0 & 1 & 2 \\
\hline LAC positivity & $5 / 18(27.8)$ & $5 / 24(20.8)$ & - \\
\hline ACL IgG positivity & $4 / 18(22.2)$ & $9 / 24(37.5)$ & - \\
\hline ACL IgM positivity & $9 / 18(50.0)$ & $5 / 24(20.8)$ & - \\
\hline Anti-b2GPI lgG positivity & $5 / 18(27.8)$ & 8/24 (33.3) & - \\
\hline Anti-b2GPI IgM positivity & 8/18 (44.4) & $12 / 24(50.0)$ & - \\
\hline Single positivity ${ }^{a}$ & 10/18 (55.5) & $13 / 24(54.1)$ & - \\
\hline Double positivity $^{b}$ & 5/18 (27.8) & $10 / 24(41.7)$ & - \\
\hline Triple positivity ${ }^{c}$ & $3 / 18(16.7)$ & $1 / 24(4.2)$ & - \\
\hline
\end{tabular}

APS antiphospholipid syndrome, aPL antiphospholipid antibodies, CTR control, SD standard deviation, LAC lupus anticoagulant, $A C L$ anticardiolipin antibodies, antib2GPI antibeta2 glycoprotein I antibodies

${ }^{a}$ Single positivity is defined as the positivity of only one between LAC, ACL lgG/M, and anti-b2GPI lgG/M

${ }^{b}$ Double positivity is defined as the positivity of two between $L A C, A C L \operatorname{lgG} / M$, and anti-b2GPI lgG/M, variously mixed

${ }^{\mathrm{C}}$ Triple positivity is defined as the positivity of three between $L A C, A C L \lg G / M$, and anti-b2GPI lgG/M, variously mixed 
Table 2 Clinical and immunological characteristics of SLE-related APS patients and SLE-"aPL carriers"

\begin{tabular}{|c|c|c|}
\hline & SLE-APS & SLE-"aPL carriers" \\
\hline Total patients & 6 & 7 \\
\hline Female-male sex & $6-0$ & $7-0$ \\
\hline Age (years, mean \pm SD) & $53 \pm 12$ & $46 \pm 12$ \\
\hline Disease duration (years, mean \pm SD) & $18 \pm 15$ & $15 \pm 11$ \\
\hline Remission (SLEDAI < 2) & 6 & 7 \\
\hline Active disease (SLEDAI > 2) & 0 & 0 \\
\hline \multicolumn{3}{|l|}{ Clinical domains } \\
\hline Cutaneous domain & 5 & 7 \\
\hline Arthritis domain & 1 & 2 \\
\hline Neurological domain & 1 & 0 \\
\hline Serositis domain & 1 & 1 \\
\hline Hematologic domain & 1 & 3 \\
\hline Renal domain & 0 & 1 \\
\hline \multicolumn{3}{|l|}{ Current therapy } \\
\hline Glucocorticoids (prednisone $\leq 5 \mathrm{mg}$ per day) & 5 & 7 \\
\hline Hydroxychloroquine & 2 & 5 \\
\hline CDMARDs (methotrexate, azathioprine, mycophenolate mofetil) & 4 & 4 \\
\hline
\end{tabular}

SLE systemic lupus erythematosus, SLEDAl systemic lupus erythematosus disease activity index, APS antiphospholipid syndrome, aPL antiphospholipid antibodies, $S D$ standard deviation, CDMARDs conventional disease-modifying anti-rheumatic drugs

alterations/reduction; $3,>66 \%$ of capillary alterations/ reduction per linear millimeter) $[15,16]$.

\section{Statistical analysis}

Continuous variables were reported as medians and interquartile range (IQR) or standard deviation (SD) when appropriate, while categorical variables as count and percentage. Normality of distribution of continuous variables was to be assessed by visual inspection. The chi-square test or Fisher's exact test was be used to compare categorical variables while the Mann-Whitney test was used to compare continuous variables. Any $p$ values equal or lower than 0.05 was considered statistically significant.

\section{Results}

\section{NVC findings}

In the APS cohort, 3 patients showed a normal NVC pattern, while 15 patients showed non-specific abnormalities. In the "aPL carriers" cohort, 8 patients showed a normal NVC pattern and 16 patients showed nonspecific abnormalities. In the CTR group, 7 patients showed a normal NVC pattern and 11 patients showed non-specific NVC abnormalities. The different NVC findings are presented in Table 3.

The number of patients with dilated capillaries was not statistically different in the three groups (APS vs "aPL carriers", $p=0.536$ and APS vs CNT, $p=1.000$, respectively), but the semi-quantitative score was significantly higher in the APS group (APS vs "aPL carriers", $p=0.009$ and APS vs CNT, $p=0.002$ ). Microhemorrhages were significantly more frequent in APS patients than in "aPL carriers" $(p=0.032)$, whereas not any significant difference was found between APS patients and the CTR group $(p=0.314)$. However, "comblike" hemorrhages (NVC pattern) were statistically more represented in the APS group (than "aPL carriers" $p=$ 0.003 , and compared with CTR $p=0.01$ ).

Among the entire cohort of patients, none showed giant capillaries at NVC, whereas a lower capillary density was detected in just one APS patient. Non-specific abnormal capillaries were observed only in APS patients (11.1\%) and CTR groups (11.1\%). A "radar" plot reporting all NVC variables is provided in Fig. 2.

\section{NVC alterations and immunological profile}

Not any significant correlation was found between the immunological profile and non-specific nailfold microvascular array abnormalities-notably, microhemorrhages, "comb-like" hemorrhages, abnormally shaped capillaries, capillary density-or specific aPL isotypes (Table 4).

\section{Discussion}

This study compares NVC microvascular findings in a cohort of APS patients and "aPL carriers" for the first time, with a control group of patients in chronic therapy with warfarin for non-immunological indications. 
Table 3 Comparison of NVC alterations between APS and "aPL carriers" and between APS and CTR group

\begin{tabular}{|c|c|c|c|c|c|}
\hline VCP evaluation & APS & "aPL carriers" & $p$-value & CTR & $p$-value \\
\hline \multicolumn{6}{|l|}{ Global pattern (\%) } \\
\hline Normal & $3(16.7)$ & $8(33.3)$ & 0.299 & $7(38.9)$ & 0.264 \\
\hline Non-specific alterations & $15(83.3)$ & $16(66.7)$ & 0.299 & $11(61.1)$ & 0.264 \\
\hline \multicolumn{6}{|l|}{ AB score, median [IQR] } \\
\hline A-score & $2.0[2.0,3.0]$ & $1.0[1.0,2.0]$ & 0.004 & $1.5[1.0,2.0]$ & 0.021 \\
\hline B-score & $0.0[0.0,0.8]$ & $0.0[0.0,0.0]$ & 0.098 & $0.0[0.0,0.0]$ & 0.674 \\
\hline \multicolumn{6}{|l|}{ Dilated capillaries } \\
\hline Median score [IQR] & $1.0[1.0,2.0]$ & $1.0[1.0,1.0]$ & 0.009 & $1.0[1.0,1.0]$ & 0.027 \\
\hline Number of patients (\%) & $17(94.4)$ & $20(83.3)$ & 0.536 & $18(100.0)$ & 1 \\
\hline \multicolumn{6}{|l|}{ Giant capillaries } \\
\hline Number of patients (\%) & $0(0.0)$ & $0(0.0)$ & - & $0(0.0)$ & - \\
\hline \multicolumn{6}{|l|}{ Microhemorrhages } \\
\hline Median score [IQR] & $1.0[0.0,1.0]$ & $0.0[0.0,1.0]$ & 0.034 & $0.0[0.0,1.0]$ & 0.186 \\
\hline Number of patients (\%) & $12(66.7)$ & $8(33.3)$ & 0.032 & $8(44.4)$ & 0.314 \\
\hline \multicolumn{6}{|l|}{ Abnormal shapes } \\
\hline No. of patients (\%) & $2(11.1)$ & $0(0.0)$ & 0.178 & $2(11.1)$ & 1 \\
\hline \multicolumn{6}{|l|}{ Reduced numerosity } \\
\hline No. of patients (\%) & $1(5.6)$ & $0(0.0)$ & 0.429 & $0(0.0)$ & 1 \\
\hline Absolute value of capillaries, median [IQR] & $9.5[9.0,10.0]$ & $10.0[9.0,10.0]$ & 0.946 & $10.5[10.0,11.8]$ & 0.010 \\
\hline \multicolumn{6}{|l|}{ Single hemorrhages } \\
\hline Median [IQR] & $0.0[0.0,0.8]$ & $0.0[0.0,0.2]$ & 0.767 & $0.0[0.0,1.0]$ & 0.461 \\
\hline No. of patients (\%) & $5(27.8)$ & $6(25.0)$ & 0.875 & $7(38.9)$ & 0.72 \\
\hline \multicolumn{6}{|l|}{ "Comb-like" hemorrhages } \\
\hline Median [IQR] & $0.5[0.0,1.0]$ & $0.0[0.0,0.0]$ & 0.007 & $0.0[0.0,0.0]$ & 0.029 \\
\hline No. of patients (\%) & $8(50)$ & $3(12.5)$ & 0.020 & $3(16.7)$ & 0.034 \\
\hline
\end{tabular}

APS antiphospholipid syndrome, aPL antiphospholipid antibodies, CTR control, IQR interquartile range

$\mathrm{NVC}$ is to date the best tool to analyze microvascular abnormalities in CTDs $[17,18]$. Additionally, NVC alterations in course of SSc are well-defined and correlate with organ involvement and disease progression, in contrast to other CTDs-such as in SLE, SjS, MCTD, and IIM-in which NVC alteration is less disease-specific [19-24].

In this investigation, both the primitive and the SLEsecondary forms of APS were considered, excluding association with SSc, IIM, and MCTD due to the presence of already defined NVC patterns (scleroderma spectrum disorders).

In 2018, the European Alliance of Associations for Rheumatology (EULAR) study group on Microcirculation in Rheumatic Diseases reported a significantly higher prevalence of tortuous capillaries, abnormal morphology, and hemorrhages in SLE patients than in healthy controls [23]. However, in our study, SLE patients were equally distributed between the APS and "aPL carriers" cohorts, thus not representing a bias for the statistical analysis.
As previously observed by other authors, APS patients showed a large variety of non-specific NVC abnormalities [25]. Particularly, microhemorrhages have been classically associated with the diagnosis of full-blown APS [8]. As a matter of fact, in our study, isolated microhemorrhages were observed in APS patients, "aPL carriers", and CTR; however, only APS patients showed a significantly higher frequency of "comb-like" parallel hemorrhages at NVC.

Bernardino et al. very recently reported the lack of association between NVC microhemorrhages in APS patients and ongoing anticoagulant treatment. Divergently, we have reported in this study a high incidence of isolated microhemorrhages in CTR patients who received a stable treatment with warfarin [26]. Hence, anticoagulant therapies might be a confounding factor for isolated microhemorrhages, but they do not appear to be associated with the NVC "comb-like" pattern. Thus, it can be suggested, also according to what previously reported by Bernardino et al., that NVC "comb-like" pattern may be a particular NVC marker in APS patients [26]. 


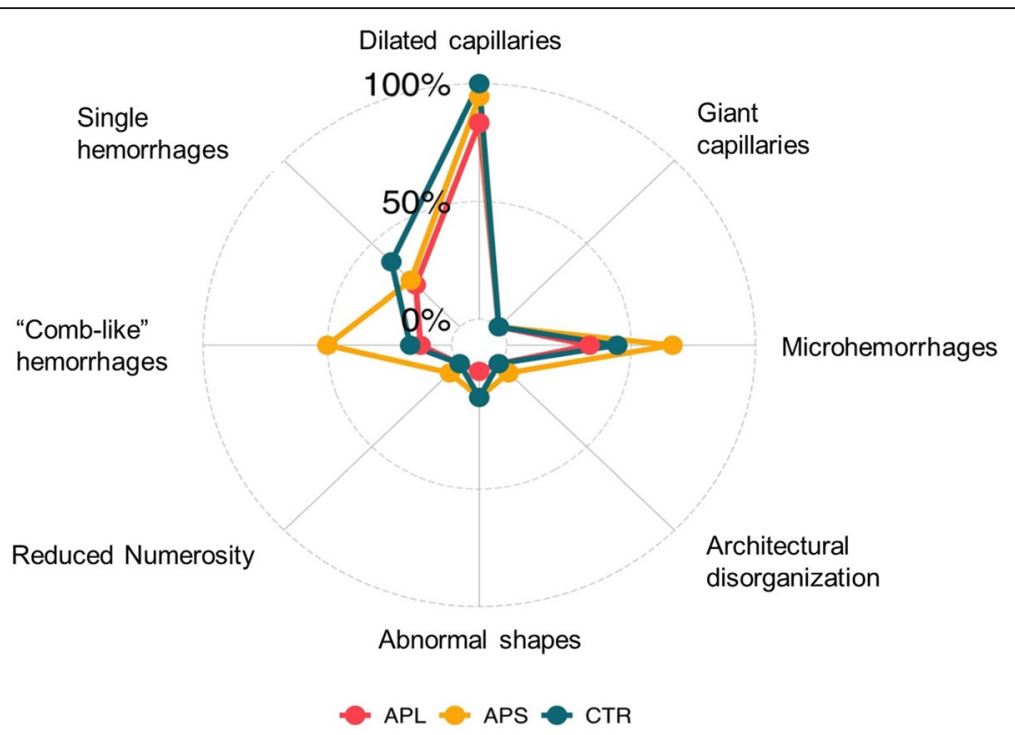

Fig. 2 Radar plot of NVC alterations. For each variable, the proportion of patients of each group with that characteristic (items' score $>0$ ) is reported. The groups are represented with different colors. APS: antiphospholipid syndrome, aPL: antiphospholipid antibodies carriers, CTR: control group

Microhemorrhages detected by NVC are relevant also in other CTDs, such as SSc, in which they are a good indicator of the steady-state level of disease activity [27, 28].

Additionally, the lack of significance of NVC alterations in "aPL carriers" may reinforce the so-called two hits hypothesis for the APS pathogenesis. Indeed, an isolated aPL positivity is not sufficient to produce an endothelium injury leading to an overt vascular thrombosis that only occurs when a second triggering factor intervenes $[29,30]$.

Regarding the correlations between NVC alterations and specific aPL positivity, Bongard et al. have described more capillary abnormalities in ACL-positive than aCLnegative SLE patients, while Bernardino et al. have reported a significant association between ACL and the absence of hemorrhage in APS patients [26, 31]. Additionally, Pyrpasopoulou et al. have reported a significant correlation between NVC microhemorrhages and APS clinical manifestations, still not any significant association with aPL subtypes was described [8,32]. Finally, a previous study detected a higher incidence of capillary hemorrhages and hemosiderin deposits in aPL $\operatorname{IgG}^{+}-$ $\mathrm{IgM}^{+}$patients, regardless of specific aCL or anti-b2GPI positivity [7].

Moving from this background, the present study aimed to investigate potential correlations between NVC alterations and different aPL subtypes in APS patients and "aPL carriers". Still, our analysis failed to find any statistically significant correlation between these parameters because of the small sample size.

Table 4 NVC alterations in APS and "aPL carriers" groups and their correlation with aPL isotypes

\begin{tabular}{lllll}
\hline & Microhemorrhages & $\boldsymbol{p}$-value & "Comb-like" & $\boldsymbol{p}$-value \\
\hline Total number & 20 & & 12 & $3(25.0)$ \\
Any positive IgG (\%) & $8(40.0)$ & 0.906 & $9(75.0)$ & 0.526 \\
Any positive IgM (\%) & $13(65.0)$ & 0.845 & $9(75.0)$ & 0.405 \\
Any positive anti-b2GPI (\%) & $16(80.0)$ & 0.541 & $7(58.3)$ & 1 \\
Any positive ACL (\%) & $12(60.0)$ & 1 & $3(25.0)$ & 1 \\
Positive ACL IgG (\%) & $7(35.0)$ & 0.915 & $6(50.0)$ & 0.822 \\
Positive ACL IgM (\%) & $8(40.0)$ & 0.659 & $3(25.0)$ & 0.31 \\
Positive anti-b2GPI IgG (\%) & $7(35.0)$ & 0.915 & $8(66.7)$ & 0.822 \\
Positive anti-b2GPI IgM (\%) & $12(60.0)$ & 0.276 & $3(25.0)$ & 0.258 \\
Positive LAC (\%) & $4(20.0)$ & 0.783 & 1 \\
\hline
\end{tabular}

ACL: anticardiolipin antibodies, anti-b2GPI: antibeta2 glycoprotein I antibodies, LAC: lupus anticoagulant 
The present study has some limitations.

Firstly, being a monocentric study, the sample of enrolled patients was numerically limited. Additionally, in the APS cohort, obstetric patients are under-represented-being only a quarter of the group-thus possibly affecting the results' interpretation. It should also be mentioned that CTR had, on average, a higher age than APS patients and "aPL carriers" as well as a strong male prevalence. The age difference could reasonably be explained by the increased clinical indication for anticoagulant therapies in older age. Still, microhemorrhages are usually not reported in elderly patients, reinforcing the suspicion of anticoagulant therapy interference [8]. The strong male prevalence in the CTR group is due to the gender-related difference in the incidence of cardiovascular disease (which is the first indication for anticoagulant therapy) [33].

In conclusion, this study highlights significant NVC differences between APS and "aPL carriers" (e.g., "comblike" hemorrhages), probably reflecting different steps in the pathogenesis of the full-blown disease. Microvascular endothelial injury could be more thoroughly identified by nailfold biopsies in both conditions, however, always taking into account the mechanical endothelial stress in course of anticoagulant therapy.

In fact, anticoagulants might be a confounding factor for the presence of isolated microhemorrhages, this latter aspect deserving further investigation in larger cohorts.

However, NVC "comb-like" hemorrhages appear to be a specific marker of APS, regardless of the concomitant anticoagulant therapy. Interestingly, it is still unclear whether the presence of these specific hemorrhages is an epiphenomenon of concomitant endothelial damage or may instead play a predictive role for other vascular complications.

Additional studies on larger cohorts of patients are needed to further characterize these preliminary data on NVC abnormalities in APS patients and "aPL carriers".

\footnotetext{
Abbreviations

APS: Antiphospholipid syndrome; NVC: Nailfold videocapillaroscopy; CTR: Control patients; aPL: Antiphospholipid antibodies; aCL: Anticardiolipin antibodies; anti-b2GPI: Antibeta2 glycoprotein I antibodies; LAC: Lupus anticoagulant; SLE: Systemic lupus erythematosus; SSc: Systemic sclerosis; SjS: Sjögren's syndrome; MCTD: Mixed connective tissue disease; IIM: Idiopathic inflammatory myopathy; IQR: Interquartile range; SD: Standard deviation; CTDs: Connective tissue diseases; EULAR: European Alliance of Associations for Rheumatology
}

\section{Acknowledgements}

We thank Dr. Sara De Gregorio for the graphic support and Dr. Luca Carmisciano for the statistical analysis.

\section{Authors' contributions}

GF and EG were involved in the conception and design of the study, acquisition of the data, basic analysis and interpretation of the data, drafting of the manuscript, and revising it critically for important intellectual content. GP was involved in the laboratory analysis. LN and BMC were involved in the acquisition of the data, interpretation of the data, and revising the manuscript for important intellectual content. SP, GP, CS, and AS were involved in the interpretation of the data, drafting of the manuscript, and revising it critically for important intellectual content. CP was involved in the execution of NVC. VS and MC were involved in the conception and design of the study, interpretation of the data, drafting of the manuscript, and revising it critically for important intellectual content. $M C$ revised the final edition. All authors read and approved the final manuscript.

Funding

None.

Availability of data and materials

The authors state they have full control of all primary data and agree to allow the journal to review their data after reasonable request.

\section{Declarations}

Ethics approval and consent to participate

This study was conducted in accordance with the principles of the Declaration of Helsinki and Good Clinical Practice. All the patients signed the written informed consent to manage their clinical data.

Consent for publication

Not applicable.

Competing interests

The authors declare that they have no competing interests.

\section{Author details}

'Laboratory of Experimental Rheumatology and Academic Division of Clinical Rheumatology, Department of Internal Medicine and Specialties (DiMl), University of Genova, IRCCS San Martino Polyclinic, Viale Benedetto XV, $n^{\circ} 6$ 16132 Genoa, Italy. ${ }^{2}$ Autoimmunity Laboratory, Department of Internal Medicine and Specialties (DiMI), University of Genova, IRCCS San Martino Polyclinic, Genoa, Italy. ${ }^{3}$ Medicine Laboratory, IRCCS San Martino Polyclinic, Genoa, Italy. ${ }^{4}$ RCCS San Martino Polyclinic, Genova - Italian Cardiovascular Network, Genoa, Italy. ${ }^{5}$ Department of Rheumatology, Ghent University Hospital - Department of Internal Medicine, Ghent University, Ghent, Belgium. ${ }^{6}$ Unit for Molecular Immunology and Inflammation, VIB Inflammation Research Center (IRC), Ghent, Belgium.

Received: 22 February 2021 Accepted: 31 May 2021

Published online: 27 June 2021

\section{References}

1. Ruiz-Irastorza G, Crowther M, Branch W, Khamashta MA. Antiphospholipid syndrome. Lancet. 2010;376(9751):1498-509. https://doi.org/10.1016/S01406736(10)60709-X.

2. Miyakis S, Lockshin MD, Atsumi T, et al. International consensus statement on an update of the classification criteria for definite antiphospholipid syndrome (APS). J Thromb Haemost. 2006;4(2):295-306. https://doi.org/1 0.1111/j.1538-7836.2006.01753.x.

3. Pengo V, Banzato A, Bison E, Bracco A, Denas G, Ruffatti A. What have we learned about antiphospholipid syndrome from patients and antiphospholipid carrier cohorts? Semin Thromb Hemost. 2012;38(4):322-7. https://doi.org/10.1055/s-0032-1304719.

4. Tektonidou MG, Andreoli L, Limper M, Tincani A, Ward MM. Management of thrombotic and obstetric antiphospholipid syndrome: a systematic literature review informing the EULAR recommendations for the management of antiphospholipid syndrome in adults. RMD Open. 2019;5(1):e000924. https:// doi.org/10.1136/rmdopen-2019-000924.

5. Candela M, Pansoni A, De Carolis ST, et al. Nailfold capillary microscopy in patients with antiphospholipid syndrome. Recenti Prog Med. 1998;89(9): 444-9.

6. Cutolo M. The most important capillaroscopic parameters in normal and pathological conditions. In: Cutolo M, editor. Atlas of capillaroscopy in rheumatic diseases. Milano: Elsevier; 2010. p. 141-3.

7. Sulli A, Pizzorni C, Cutolo M. Nailfold videocapillaroscopy abnormalities in patients with antiphospholipid antibodies. J Rheumatol. 2000;27(6):1574-6.

8. Pyrpasopoulou A, Triantafyllou A, Anyfanti P, Douma S, Aslanidis S. Capillaroscopy as a screening test for clinical antiphospholipid 
syndrome. Eur J Intern Med. 2011;22(6):e158-9. https://doi.org/10.1016/j. ejim.2011.07.007.

9. Aringer M, Costenbader K, Daikh D, Brinks R, Mosca M, Ramsey-Goldman R, et al. European League Against Rheumatism/American College of Rheumatology classification criteria for systemic lupus erythematosus. Arthritis Rheumatol. 2019;71(9):1400-12. https://doi.org/10.1002/art.40930.

10. Van den Hoogen F, Khanna D, Fransen J, et al. 2013 classification criteria for systemic sclerosis: an American College of Rheumatology/European League against Rheumatism collaborative initiative. Arthritis Rheum. 2013;65(11): 2737-47. https://doi.org/10.1002/art.38098.

11. Shiboski CH, Shiboski SC, Seror R, Criswell LA, Labetoulle M, Lietman TM, et al. 2016 American College of Rheumatology/European League Against Rheumatism classification criteria for primary Sjögren's syndrome: a consensus and data-driven methodology involving three international patient cohorts. Arthritis Rheumatol. 2017;69(1):35-45. https://doi.org/10.1 002/art.39859.

12. Kasukawa R, Tojo T, Miyawaki S. Preliminary diagnostic criteria for classification of mixed connective tissue disease. In: Kasukawa R, Sharp G, editors. Mixed connective tissue disease and antinuclear antibodies. Amsterdam: Elsevier; 1987. p. 41-7.

13. Lundberg IE, Tjärnlund $\mathrm{A}$, Bottai $\mathrm{M}$, Werth VP, Pilkington C, Visser $\mathrm{M}$, et al. 2017 European League Against Rheumatism/American College of Rheumatology classification criteria for adult and juvenile idiopathic inflammatory myopathies and their major subgroups. Ann Rheum Dis. 2017; 76(12):1955-64. https://doi.org/10.1136/annrheumdis-2017-211468.

14. Smith V, Herrick AL, Ingegnoli F, EULAR Study Group on Microcirculation in Rheumatic Diseases and the Scleroderma Clinical Trials Consortium Group on Capillaroscopy, et al. Standardization of nailfold capillaroscopy for the assessment of patients with Raynaud's phenomenon and systemic sclerosis. Autoimmun Rev. 2020;19:102458.

15. Cutolo M, Pizzorni C, Secchi ME, Sulli A. Capillaroscopy. Best Pract Res Clin Rheumatol. 2008;22(6):1093-108. https://doi.org/10.1016/j.berh.2008.09.001

16. Sulli A, Secchi ME, Pizzorni C, Cutolo M. Scoring the nailfold microvascular changes during the capillaroscopic analysis in systemic sclerosis patients. Ann Rheum Dis. 2008;67(6):885-7. https://doi.org/10.1136/ard.2007.079756.

17. Cutolo M, Melsens K, Herrick AL, Foeldvari I, Deschepper E, de Keyser F, et al. EULAR Study Group on Microcirculation in Rheumatic Diseases. Reliability of simple capillaroscopic definitions in describing capillary morphology in rheumatic diseases. Rheumatology. 2018;57(4):757-9. https:// doi.org/10.1093/rheumatology/kex460.

18. Cutolo M, Paolino S, Smith V. Nailfold capillaroscopy in rheumatology: ready for the daily use but with care in terminology. Clin Rheumatol. 2019;38(9): 2293-7. https://doi.org/10.1007/s10067-019-04716-w.

19. Sulli A, Paolino S, Pizzorni C, Ferrari G, Pacini G, Pesce G, et al. Progression of nailfold capillaroscopic patterns and correlation with organ involvement in systemic sclerosis: a 12-year study. Rheumatology. 2020;59(5):1051-8. https://doi.org/10.1093/rheumatology/kez374.

20. Pizzorni C, Cutolo M, Sulli Aet al. Long-term follow-up of nailfold videocapillaroscopic changes in dermatomyositis versus systemic sclerosis patients. Clin Rheumatol 2018; 37:2723-2729, 10, DOI: https://doi.org/10.1 007/s10067-018-4211-2.

21. Soubrier C, Seguier J, Di Costanzo MP, et al. Nailfold videocapillaroscopy alterations in dermatomyositis, antisynthetase syndrome, overlap myositis, and immune-mediated necrotizing myopathy. Clin Rheumatol. 2019;38(12): 3451-8. https://doi.org/10.1007/s10067-019-04710-2.

22. Paolino S, Ferrari G, Pizzorni C, et al. Long-term follow-up of nailfold videocapillaroscopic microvascular parameters in mixed connective tissue disease versus systemic sclerosis patients: a retrospective cohort study. Clin Exp Rheumatol. 2019;37(Suppl 119):102-7.

23. Cutolo M, Melsens K, Wijnant S, Ingegnoli F, Thevissen K, de Keyser F, et al. Nailfold capillaroscopy in systemic lupus erythematosus: a systematic review and critical appraisal. Autoimmun Rev. 2018;17(4):344-52. https://doi.org/1 0.1016/j.autrev.2017.11.025.

24. Melsens K, Leone MC, Paolino S, et al. Nailfold capillaroscopy in Sjögren's syndrome: a systematic literature review and standardised interpretation. Clin Exp Rheumatol. 2020;38(Suppl 126):150-7.

25. Vaz JL, Dancour MA, Bottino DA, Bouskela E. Nailfold videocapillaroscopy in primary antiphospholipid syndrome (PAPS). Rheumatology. 2004;43(8):10257. https://doi.org/10.1093/rheumatology/keh233.

26. Bernardino V, Rodrigues A, Lladó A, Panarra A. Nailfold capillaroscopy and autoimmune connective tissue diseases in patients from a Portuguese nailfold capillaroscopy clinic. Rheumatol Int. 2020;40(2):295-301. https://doi. org/10.1007/s00296-019-04427-0.

27. Pignataro F, Maglione W, Minniti A, Sambataro D, Sambataro G, Campanaro $F$, et al. NEMO score in nailfold videocapillaroscopy is a good tool to assess both steady state levels and overtime changes of disease activity in patients with systemic sclerosis: a comparison with the proposed composite indices for this disease status entity. Arthritis Res Ther. 2019;21(1):258. https://doi. org/10.1186/s13075-019-2032-6.

28. Andracco R, Irace R, Zaccara E, Vettori S, Maglione W, Riccardi A, et al. The cumulative number of micro-haemorrhages and micro-thromboses in nailfold videocapillaroscopy is a good indicator of disease activity in systemic sclerosis: a validation study of the NEMO score. Arthritis Res Ther. 2017;19(1):133. https://doi.org/10.1186/s13075-017-1354-5.

29. Meroni PL, Borghi MO, Raschi E, Ventura D, Sarzi Puttini PC, Atzeni F, et al. Inflammatory response and the endothelium. Thromb Res. 2004;114(5-6): 329-34. https://doi.org/10.1016/j.thromres.2004.06.045.

30. Meroni PL, Chighizola CB, Rovelli F, Gerosa M. Antiphospholipid syndrome in 2014: more clinical manifestations, novel pathogenic players and emerging biomarkers. Arthritis Res Ther. 2014;16(2):209. https://doi.org/10.11 86/ar4549.

31. Bongard O, Bounameaux H, Miescher PA, De Moerloose P. Association of anticardiolipin antibodies and abnormal nailfold capillaroscopy in patients with systemic lupus erythematosus. Lupus. 1995;4(2):142-4. https://doi.org/1 $0.1177 / 096120339500400211$

32. Aslanidis S, Pyrpasopoulou A, Doumas M, Triantafyllou A, Chatzimichailidou $\mathrm{S}$, Zamboulis C. Association of capillaroscopic microhaemorrhages with clinical and immunological antiphospholipid syndrome. Clin Exp Rheumatol. 2011;29(2):307-9.

33. Chugh SS, Havmoeller R, Narayanan K, Singh D, Rienstra M, Benjamin EJ, et al. Worldwide epidemiology of atrial fibrillation: a Global Burden of Disease 2010 Study. Circulation. 2014;129(8):837-47. https://doi.org/10.1161/ CIRCULATIONAHA.113.005119.

\section{Publisher's Note}

Springer Nature remains neutral with regard to jurisdictional claims in published maps and institutional affiliations.

Ready to submit your research? Choose BMC and benefit from:

- fast, convenient online submission

- thorough peer review by experienced researchers in your field

- rapid publication on acceptance

- support for research data, including large and complex data types

- gold Open Access which fosters wider collaboration and increased citations

- maximum visibility for your research: over $100 \mathrm{M}$ website views per year

At $\mathrm{BMC}$, research is always in progress.

Learn more biomedcentral.com/submissions 